\title{
COMPORTAMENTO DO FATOR DE NECROSE TUMORAL E DA PROTEÍNA C REATIVA EM HEPATECTOMIA SIMULTÂNEA COM COLECTOMIA EM RATOS
}

\author{
BEHAVIOR OF THE TUMOR NECROSIS FACTOR AND C-REACTIVE PROTEIN IN \\ SIMULTANEOUS HEPATECTOMY PLUS COLECTOMY IN RATS
}

\author{
Hamilton Luiz Xavier Funes, TCBC-SP' ; Rita de Cássia Martins Alves da Silva²; \\ Renato Ferreira da Silva, TCBC-SP³ ${ }^{3}$ Antonio Pelosi de Moura Leite, ECBC-SP'; \\ Fabiana Longui Segantini ${ }^{5}$; Sueli Calvi
}

\begin{abstract}
RESUMO: Objetivo: Observar o comportamento do fator de necrose tumoral-a (TNF $\alpha$ ) e da proteína C reativa (PCR) em cirurgias simultâneas de fígado e intestino. Método: Para este objetivo foi desenvolvido um modelo experimental, no qual foram operados quarenta ratos da raça Wistar, divididos em quatros grupos: grupo controle, grupo 1 com ratos submetidos à hepatectomia a 70\%, grupo 2 com ratos submetidos à colectomia e grupo $3 \mathrm{com}$ cirurgia simultânea de hepactetomia e colectomia. Em todos os grupos foram dosados TNF $\alpha$ e PCR uma hora após o procedimento. Os animais foram mortos em seguida. Resultados: Os valores encontrados mostraram alteração nas dosagens desses elementos nos diversos grupos, sendo que no grupo 3 houve aumento significativo do TNF $\alpha$ e queda de PCR. Conclusão: Quanto mais complexo se tornou o ato cirúrgico os níveis sangüíneos de TFN $\alpha$ aumentaram e os níveis sangüíneos da PCR diminuíram significativamente (Rev. Col. Bras. Cir. 2005; 32(2): 94-99)
\end{abstract}

Descritores: Neoplasias colorretais; Hepatectomia; Colectomia; Fator de necrose Tumoral; Proteína C; Ratos, Wistar.

\section{INTRODUÇÃO}

O carcinoma colorretal é o segundo tipo de câncer mais comum, e responsável pela segunda causa de morte nos EUA $^{1-3}$. No Brasil, ocupa o sexto lugar em incidência de doenças neoplásicas e, somente em São Paulo, 1815 casos por 1000.000 habitantes são diagnosticados por ano ${ }^{4}$. O fígado é o sítio mais comum de metástases, que podem ser sincrônicas (15 a 25\%), ou metacrônicas (15 a 40\%). A ressecção cirúrgica é o melhor tratamento, tanto do tumor primário, quanto das metástases hepáticas ${ }^{1}$.

A partir das publicações de Flanagan e Foster ${ }^{5}$, as ressecções hepáticas por metástases de tumores colorretais, têm aumentado significativamente e, a partir do momento em que as ressecções das lesões metacrônicas mostraram resultados encorajadores, lesões sincrônicas passaram também a ser tratadas por hepatectomia, concomitante à colectomia, havendo no entanto, algumas controvérsias nesta conduta ${ }^{6}$.

Quando há metástases hepáticas sincrônicas, alguns autores são de opinião que se deva fazer a ressecção hepática em prazo de dois a três meses após a ressecção do tumor primário, levando-se em conta, razões técnicas e oncológicas ${ }^{1,-9}$.

Questiona-se ainda, se a hepatectomia deva ser feita antes ou após a ressecção intestinal ${ }^{10}$. O que sabemos, no entanto, é que nas ressecções combinadas, aumenta-se o trau- ma cirúrgico, com elevação dos níveis séricos de citocinas, que podem influenciar o resultado da cirurgia ${ }^{11}$.

$\mathrm{O}$ aumento das citocinas inflamatórias, que atuam como agentes mediadores da inflamação e da imunidade ${ }^{12}$, surge em resposta à fase aguda após cirurgias. Entre as citocinas inflamatórias, o fator de necrose tumoral alfa (TNF $\alpha)$, promove a regeneração hepática, podendo também induzir à falência hepática em humanos e em animais de experimentação ${ }^{13}$. A liberação de citocinas inflamatórias em cirurgias extensas, pode também contribuir para a alta incidência de complicações pós-operatórias ${ }^{30}$.

O mecanismo exato porque tal fato ocorre, não é bem conhecido, mas pode ser explicado pelo aumento de citocinas inflamatórias, como a interleucina 1beta (IL-1beta) e TNF $\alpha$, com inibição da proliferação do hepatócito ${ }^{14}$.

Citocinas inflamatórias, inclusive TNFa e citocinas induzidas, como IL-6, desempenham importante papel na regeneração experimental em ratos com hepatectomias parciais, indicando uma estreita relação entre a resposta imunológica extra-hepática, inflamação e regeneração ${ }^{15}$.

O nível plasmático de algumas proteínas, chamadas proteínas plasmáticas de fase aguda negativa, como a albumina, decresce; enquanto o nível das proteínas plasmáticas de fase aguda positiva, como a proteína $\mathrm{C}$ reativa (PCR), eleva-se ${ }^{16}$. Esta pesquisa experimental procurou de-

1. Cirurgião Geral.

2. Professora Doutora Adjunta do Departamento de Clínica Médica da Faculdade de Medicina de São José do Rio Preto - FAMERP; Hepatologista da Unidade de Cirurgia e Transplante de Fígado e Delgado do Hospital de Base FUNFARME/FAMERP.

3. Professor Doutor Adjunto do Departamento de Cirurgia da Faculdade de Medicina de São José do Rio Preto - FAMERP; Chefe da Unidade de Cirurgia e Transplante de Fígado e Delgado do Hospital de Base FUNFARME/FAMERP.

4. Cirurgião Geral.

5. Bióloga do Laboratório especializado em Gastroenterologia do Hospital de Base FUNFARME/FAMERP.

6. Bióloga, responsavel pelo Laboratório de Pesquisa na Área de Doenças Tropicais da UNESP, Botucatu, SP.

Recebido em 15/12/2004

Aceito para publicação em 04/01/2005

Pesquisa experimental desenvolvida na Faculdade de Medicina de São José do Rio Preto - FAMERP; Tese de doutorado do Curso de Pós-Graduação em Medicina Interna da Faculdade de Medicina de São José do Rio Preto - FAMERP. 
monstrar, que os níveis plasmáticos de TNF $\alpha$ e PCR, se alteram de acordo com a magnitude da cirurgia, observando-se o comportamento desses níveis em cirurgias simultâneas de fígado e intestino.

\section{MÉTODO}

Este estudo experimental terminal foi realizado no biotério da Faculdade de Medicina de São José do Rio Preto (FAMERP), São Paulo, após aprovação da comissão de ética de cirurgia experimental, processo ${ }^{\circ}$ F-001-001501/2001. Foram operados 40 ratos da raça Wistar pesando entre 200 e 300 gramas. Os animais foram divididos em quatro grupos de 10 animais: o grupo controle (GC) foi submetido à laparotomia; grupo 1 (G1) submetido à hepatectomia; grupo 2 (G2) submetido à colectomia e o grupo 3 (G3) submetido a colectomia e hepatectomia simultâneas.

No período pré-operatório, os animais foram colocados em gaiolas coletivas com luminosidade moderada, temperatura ambiente entre 25 e $30^{\circ} \mathrm{C}$, submetidos ao mínimo contato humano e mantidos em jejum por um período de 12 horas até o procedimento cirúrgico.

Os ratos foram anestesiados por inalação de halotano 1 a $2 \%$, após aplicação de $1 \mathrm{ml}$ de solução composta de $2,5 \mathrm{mg}$ de midazolan e 18,75 mg de Ketamina, por via subcutânea como pré-anestésico, e em seguida submetidos à tricotomia e antissepsia.

Os procedimentos cirúrgicos comuns a todos os grupos foram: 1) imobilização do animal em decúbito dorsal, fixo em placa de madeira, empregando-se fita de esparadrapo nos membros; 2) tricotomia da região abdominal anterior e antissepsia da pele com solução de polivinilpirrolidona-iodo, e, 3) laparotomia através de incisão mediana de $4 \mathrm{~cm}$ de extensão, a partir do apêndice xifóide.

Os procedimentos cirúrgicos no grupo 1 foram hepatectomia parcial de aproximadamente $70 \%$ do parênquima hepático que , corresponde à retirada dos lobos médio e lateral esquerdo. Esta técnica padronizada por Higgens e Anderson ${ }^{17} \mathrm{e}$ publicada e em 1932, consiste na mobilização dos lobos hepáticos por secção do ligamento falciforme e de parte do pequeno omento, inferiormente. Com uma delicada pressão sobre o tórax e abdome do animal, os lobos médios e esquerdo do fígado se apresentam através da incisão cirúrgica e são delicadamente tracionados para cima. Um fio de algodão sem agulha 4.0 é colocado em volta desses dois lobos o mais próximo possível da veia cava e ligados em bloco, englobando os pedículos da veia porta e das veias supra-hepáticas correspondentes. A fim de prevenir a estenose da veia hepática direita, evita-se realizar a ligadura muito próxima à veia cava inferior. $\mathrm{O}$ parênquima hepático será ressecado cerca de 2 a $3 \mathrm{~mm}$ do nó cirúrgico.

Para o grupo 2 foram realizadas colectomia com ressecção de um segmento de cólon esquerdo de aproximadamente $1 \mathrm{~cm}, \log$ acima da reflexão peritoneal. A reconstrução do trânsito foi feita através de anastomose término-terminal em plano único com fio monofilamentar.

No grupo 3 fez-se uso de: 1) colectomia como descrita no grupo 2, e 2) hepatectomia como descrita no grupo 1 .
A síntese da parede abdominal foi realizada de modo idêntico em todos os grupos de animais. O peritôneo e a aponeurose constituiram o primeiro plano de sutura contínua com fio mononylon com agulha 3.0. A pele foi fechada com fio mononylon com agulha 4.0. Durante a recuperação anestésica todos os ratos foram mantidos em tenda fechada com oxigênio.

Na coleta do material para verificação dos níveis de TNF $\alpha$ e PCR nos animais do experimento, os seguintes procedimentos foram realizados: 1) relaparotomia com inventário da cavidade abdominal uma hora após à primeira operação, com anestesia do animal por inalação; 2) toracotomia transdiafragmática; 3 ) punção cardíaca com coleta de 3 a $4 \mathrm{ml}$ de sangue para dosagem de TNFa e PCR; 4) morte do animal por exanguinação; 5) centrifugação do sangue que foi acondicionado em alíquotas de $1 \mathrm{ml}$ e conservado em freezer a menos $70^{\circ}$ graus para posterior medida dos níveis de TNF $\alpha$ e da PCR.

A dosagem do TNF $\alpha$ e PCR foram realizadas no Laboratório do Departamento de Doenças Tropicais e Diagnóstico por Imagem da Faculdade de Medicina, UNESP, Botucatu, SP. As concentrações de TNF no soro dos grupos estudados foram determinadas usando-se um kit para ELISA ( R \& D Systems, Minneapolis, MN). A PCR foi determinada pelo método nefelométrico.

\section{RESULTADOS}

O fator de necrose tumoral dosado nos quatro grupos de ratos operados apresentou os resultados descritos na Tabela 1. As dosagens de TNF- $\alpha$ PCR, dos animais 3, 4 e 5 do grupo controle não foram realizadas devido à hemólise do material.

Para verificar se houve diferença entre os grupos, foi realizado teste de Kruskal-Wallis para comparar as médias das dosagens do TNFa entre os grupos. O teste de Kruskal-Wallis mostrou valores $\mathrm{p}<0,0001$ demonstrando que houve diferença significante entre os grupos. O teste Dunn foi realizado para comparações múltiplas entre os grupos (2 a 2) (Tabela 2).

O teste de Dunn mostrou que o grupo controle não diferiu dos grupos 1(hepatectomia)e 2(colectomia) e diferiu significantemente do grupo 3(colectomia com hepatectomia). O G1 diferiu dos G2 e G3, mas G2 não diferiu de G3. Este resultado indica que após hepatectomia a produção do TNF- $\alpha$ não difere daquele encontrado no grupo controle, por outro lado a diferença significante entre o grupo controle e o G3 indica que após a hepatectomia e colectomia simultânea ocorre produção de TNF $\alpha$ significantemente maior em relação ao grupo controle.

Com relação ao grupo 1 , o teste de Dunn mostrou que o mesmo diferiu significativamente dos grupos 2 e 3 . Este resultado demonstra que a produção de TNF $\alpha$ após hepatectomia foi significantemente menor do que após colectomia ou após hepatectomia mais colectomia simultâneas. Contudo não houve diferença na produção de TNF $\alpha$ quando foram comparados colectomia com hepatectomia mais colectomia simultâneas. A PCR dosada nos quatro grupos de ratos operados apresentou os resultados descritos na Tabela 3 .

Para verificar se houve diferença entre os grupos, foi realizado o teste de Kruskal-Wallis para comparar as médias 
Tabela 1 - Resultados das dosagens de TNF- $\alpha$ nos diversos grupos de ratos estudados.

\begin{tabular}{ccccc}
\hline \multirow{2}{*}{$\mathbf{N}^{\mathbf{0}}$} & \multicolumn{4}{c}{ Grupos } \\
\cline { 2 - 5 } & GC & G1 & $\mathbf{G 2}$ & $\mathbf{G 3}$ \\
\hline 1 & 147 & 138 & 204 & 417 \\
2 & 131 & 146 & 236 & 328 \\
3 & $\mathrm{nr}$ & 127 & 241 & 361 \\
4 & $\mathrm{nr}$ & 116 & 206 & 403 \\
5 & $\mathrm{nr}$ & 147 & 263 & 276 \\
6 & 156 & 131 & 304 & 388 \\
7 & 171 & 115 & 317 & 326 \\
8 & 181 & 112 & 308 & 406 \\
9 & 176 & 132 & 221 & 336 \\
10 & 169 & 107 & 364 & 298 \\
\hline Media & $\mathbf{1 6 1 , 7}$ & $\mathbf{1 2 7 , 1 0}$ & $\mathbf{2 6 6 , 4 0}$ & $\mathbf{3 5 3 , 9 0}$ \\
S D & $\mathbf{1 7 , 8 3}$ & $\mathbf{1 4 . 1 9 3}$ & $\mathbf{5 4 , 1 7 5}$ & $\mathbf{4 8 , 6 2 9}$ \\
\hline
\end{tabular}

$n r=$ não realizados .

Tabela 2 - Resultados do teste de Dunn para comparar os valores médios do TNF- $\alpha$ nos grupos (2 a 2).

\begin{tabular}{cc}
\hline Comparação & Valor $\boldsymbol{p}$ \\
\hline GC x G1 & $p>0,05$ \\
GC x G2 & $p>0,05$ \\
GC x G3 & $p<0,01$ \\
G1 x G2 & $p<0,01$ \\
G1 x G3 & $p<0,001$ \\
G2 x G3 & $p>0,05$ \\
\hline
\end{tabular}

das dosagens do PCR entre os grupos, que mostrou valor $p<0,0001$ demonstrando que houve diferença estatística significante entre os grupos. O teste de Dunn foi realizado para comparações múltiplas entre os grupos (2 a 2) (Tabela 4). $\mathrm{O}$ teste de Dunn mostrou que o grupo controle diferiu dos grupos 1 e 2, mas não diferiu do grupo 3. Isto indicou que a produção de PCR após a colectomia e também após a hepatectomia foi maior do que no grupo controle, e após cirurgias simultâneas foi semelhante ao mesmo.

O grupo 1 não diferiu do grupo 2, indicando que não houve diferença significante após hepatectomia quando comparadas à colectomia isolada. Quando foram comparadas hepatectomia e operações simultâneas as primeiras mostraram produção de PCR significativamente maior. Não houve diferença significante de PCR entre os grupos 2 e 3 .

\section{DISCUSSÃO}

Não resta dúvida de que, no momento, o tratamento cirúrgico é o único procedimento que pode propiciar a cura aos pacientes portadores de metástase hepática de câncer colorretal ${ }^{4}$ propiciando uma sobrevida em cinco anos de 25 a $50 \%$ 4,6,18-23.

Quando uma metástase hepática é diagnosticada durante a laparotomia para ressecção de um carcinoma colorretal, a melhor estratégia para o seu tratamento não está claramente definida ${ }^{20,24,25}$. Em 1993, Foster ${ }^{26}$ recomen-
Tabela 3 - Resultados das dosagens de PCR nos diversos grupos de ratos estudados.

\begin{tabular}{ccccc}
\hline $\mathbf{N}^{\mathbf{o}}$ & \multicolumn{4}{c}{ Grupos } \\
\cline { 2 - 5 } & $\mathbf{G C}$ & $\mathbf{G 1}$ & $\mathbf{G 2}$ & $\mathbf{G 3}$ \\
\hline 1 & 0,9 & 44,3 & 31,0 & 17,0 \\
2 & 1,0 & 46,1 & 26,1 & 8,0 \\
3 & $\mathrm{nr}$ & 47,0 & 26,0 & 14,0 \\
4 & $\mathrm{nr}$ & 59,5 & 31,2 & 16,0 \\
5 & $\mathrm{nr}$ & 65,6 & 29,0 & 10,0 \\
6 & 1,0 & 67,9 & 36,0 & 17,0 \\
7 & 0,8 & 48,6 & 37,1 & 9,0 \\
8 & 1,1 & 71,0 & 46,0 & 13,0 \\
9 & 1,0 & 48,9 & 39,0 & 21,0 \\
10 & 1,0 & 77,0 & 48,0 & 17,0 \\
\hline media & $\mathbf{1 , 0 0 0}$ & $\mathbf{5 7 , 7 0 0}$ & $\mathbf{3 4 , 9 0 0}$ & $\mathbf{1 4 , 2 0 0}$ \\
SD & $\mathbf{0 , 0 0 0}$ & $\mathbf{1 2 , 1 1 1}$ & $\mathbf{7 , 7 5 2}$ & $\mathbf{4 , 1 8 5}$ \\
\hline
\end{tabular}

$n r=$ não realizado.

Tabela 4 - Resultados do teste de Dunn para comparar os valores médios do PCR nos grupos (2 a 2).

\begin{tabular}{cl}
\hline Comparação & Valor $p$ \\
\hline GC x G1 & $p<0,001$ \\
GC x G2 & $p<0,001$ \\
GC x G3 & $p>0,05$ \\
G1 x G2 & $p>0,05$ \\
G1 x G3 & $p<0,001$ \\
G2 x G3 & $p>0,05$ \\
\hline
\end{tabular}

dou que, se as condições do paciente, tipo de incisão e experiência do cirurgião permitirem, uma ressecção fácil de lesão periférica pode ser feita simultaneamente com o tumor primário. Outros autores acreditam que seria melhor adiar a ressecção hepática ${ }^{1,7,8,20}$.

Vogt et al. ${ }^{6} \mathrm{em} 1991$, publicaram resultados da operação combinada e da ressecção hepática isolada, em média dois meses após a intervenção cirúrgica do tumor primário, não encontrando diferença significativa entre os dois grupos no que diz respeito à morbidade, mortalidade e tempo de sobrevida. Outros autores também concluíram que o tempo da operação, se combinado ou tardio, não tem impacto na sobrevida $6,10,11,20$.

Tem sido praticamente consenso que pacientes com metástases sincrônicas em até dois segmentos hepáticos, podem ser submetidos à ressecção simultânea com a cirurgia colorretal, mas ressecções de maior porte devem ser realizadas posteriormente ${ }^{4,6,10,11}$. Lygidakis et al. ${ }^{27}$, em lesões mais avançadas propõem a cirurgia hepática em dois estágios.

Segundo Nordlinger et al. ${ }^{28}$, as complicações operatórias, das quais as mais sérias são sangramento e insuficiência hepática, aumentaram a mortalidade para $21 \%$ e $16 \%$, respectivamente, com a ressecção hepática alargada, simultânea com o tumor primário. A causa deste aumento é provavelmente multifatorial ${ }^{29}$, e não está ainda bem definida ${ }^{30}$. Bolton et al. ${ }^{29}$, relatam que fístula na anastomose colônica e sepse foram responsáveis pela morte de dois pacientes, e outros 
três morreram por falência hepática após ressecção maciça. Algumas das razões mencionadas para desencorajar a ressecção simultânea são: o aumento da mortalidade operatória, associação de procedimento contaminado e limpo e necessidade de um estadiamento oncológico intra-operatório ${ }^{20}$.

Elias et al. ${ }^{10}$ admitem com segurança que um número restrito de cirurgias é preferível sob o ponto de vista oncológico, podendo haver benefícios com a ressecção simultânea e precoce das metástases, evitando sua disseminação ${ }^{11}$.

Além dos aspectos técnicos temos a observar que o fígado é o órgão que mais libera e metaboliza citocinas. Durante a fase aguda da inflamação, em consequiência de uma abundante liberação de citocinas inflamatórias, a expressão genética e o modelo biossintético dos hepatócitos são marcadamente alterados. A concentração de certas proteínas do plasma, como as proteínas plasmáticas de fase aguda, na maior parte de origem hepática, é submetida a dramáticas mudanças em resposta à liberação local e sistêmica de uma série de citocinas e eicosanoides ${ }^{16}$. A síntese do grupo de proteínas hepáticas especificas do plasma, conhecidas como de reação à fase aguda, aumentam surpreendentemente ${ }^{31-32}$. A alteração da concentração sérica dessas proteínas é o resultado direto da alteração da síntese protéica realizada pelo hepatócito sob influência das citocinas ${ }^{33}$. Proteínas de fase aguda, sintetizadas durante exposição à infecção ou injúria tecidual, têm sido demonstradas como fundamentais na proteção do animal aos vários insultos inflamatórios. A PCR conhecida por ser um mediador antiinflamatório que está envolvida na função microbicida e fagocítica, bloqueia a atividade da IL- ${ }^{34}$.

A reação de fase aguda representa um dos melhores fenômenos conhecidos de como as citocinas podem afetar a função hepática ${ }^{35}$. Todas as células normalmente existentes no fígado têm capacidade de produzir citocinas por estímulo de células ao seu redor ou estimuladas por elas mesmas, para aumentar a resposta inflamatória ${ }^{33}$. A função das citocinas na regeneração hepática tem sido motivo de discussão em vários estudos ${ }^{36-37}$. Muitas citocinas provocam mitose do hepatócito in vitro, mas sua importância in vivo não está clara, e recentes estudos sugerem um controle central de função pelo TNF- $\alpha$ na regeneração hepática após toxicidade e hepatectomia de $70 \%{ }^{33}$. Entre as citocinas inflamatórias, o TNF- $\alpha$ promove a proliferação dos hepatócitos durante a regeneração hepática, mas pode induzir a falência hepática em humanos ou animais de experimentação ${ }^{13}$.

No presente estudo, partimos da hipótese de que nas hepatectomias realizadas simultaneamente com colectomia para o tratamento do câncer de cólon, há um aumento importante nos níveis plasmáticos de citocinas inflamatórias, o que pode contribuir para explicar um maior número de complicações pós-operatórias que ocorrem nestas operações. Os níveis da PCR também foram dosados para avaliar a importante função hepática de restaurar a homeostase após infecção, inflamação ou injúria. As alterações observadas são resultado da reação inflamatória aguda que ocorre após o trauma cirúr- gico descrito em vários trabalhos ${ }^{14,16,30-33,38}$. Estudos recentes têm demonstrado que o aumento na produção de citocinas inflamatórias ocorre como uma resposta à fase aguda após a cirurgia ${ }^{15,16,33,39-40}$.

Estudos relatam que a ressecção simultânea do fígado e intestino reduz significativamente a síntese protéica no fígado remanescente quando comparada somente à hepatectomia ${ }^{14}$, o que pode induzir também a uma diminuição da síntese de proteínas de fase aguda no fígado ${ }^{30}$. Como as proteínas de fase aguda são voltadas para proteção contra agressões inflamatórias ${ }^{34,41}$, a diminuição das mesmas pode permitir que os pacientes fiquem mais susceptíveis às complicações pós-operatórias ${ }^{30}$. Após hepatectomia extensa em ratos, Tsutsumi et al. ${ }^{38}$ mostram que a supressão precoce das citocinas melhora a função hepática e facilita a regeneração do fígado, permitindo extensão da ressecção com redução do risco de falência hepática.

Nos animais do G1, dosagens de TNF $\alpha$ foram menores do que as encontradas no grupo controle, porém sem significação estatística. TNF $\alpha$ exógeno estimula a síntese de DNA em roedores e acelera a regeneração da massa hepática após hepatectomia parcial, entretanto, não há aumento na concentração de TNF $\alpha$ sérico ${ }^{42}$. Aumento nas concentrações de TNF $\alpha$ e IL-1 tem sido observado no estresse cirúrgico ativado pelos linfócitos e outras células para produzir IL- $6^{43}$. TNF $\alpha$ e IL-1 são capazes de iniciar a produção de IL-6 em várias células ${ }^{14}$, e recentemente, tem sido demostrado que IL-6 é o mais potente indutor da síntese de proteína de fase aguda nos hepatócitos humanos ${ }^{14}$.

Na regeneração hepática, a IL-6 aumenta a transcrição, levando os hepatócitos a deixarem sua fase de inércia e entrar na fase pré-replicativa ${ }^{44}$. As dosagens de $\mathrm{TNF} \alpha$ nos grupos 2 e 3 foram maiores quando comparadas ao grupo controle e grupo1 sendo os maiores valores encontrados no grupo 3, no qual a hepatectomia foi realizada simultaneamente com colectomia. Em doses adequadas, o TNF $\alpha$ orquestra a resposta inflamatória localizada, ao iniciar, manter e finalizar a inflamação local e circunscrita. Respostas fisiológicas exageradas ocorrem sob grandes concentrações de TNF $\alpha$ e resultam em aberrações de coagulação, adesão celular e integridade vascular ${ }^{45}$. É importante reconhecer que a toxicidade do TNF $\alpha$ e outras citocinas podem estar sinergicamente aumentadas por outros fatores. Além do mais, o processo inflamatório mediado por citocinas inflamatórias é geralmente benéfico ao hospedeiro, mas intrinsicamente danoso aos tecidos vizinhos. A falência múltipla de órgãos é tida como uma reação inflamatória incontrolada, com altos níveis circulantes de citocinas 46,47

Em decorrência do prolongado aumento da resposta inflamatória que pode induzir falência e disfunção hepáti$\mathrm{ca}^{47}$, insulto e dano tecidual acentuados, resultado de cirurgias extensas, também podem contribuir para certas complicações ${ }^{30}$. Finalizando, a diminuição da regeneração hepática, da síntese de reagentes de fase aguda e do aumento de endotoxinas no plasma, podem ser responsáveis pela alta incidência de complicações no pós-operatório de hepatectomia simultânea ${ }^{14,30}$. 


\begin{abstract}
Background: The aim of this experimental study was to observe the behavior of Tumor Necrosis Factor and C-Reative Protein in simultaneous colectomy plus hepatectomy. Methods: In this experimental model, 40 Wistar rats underwent surgery. They were divided into four groups: the control group; group 1, rats submitted to hepatectomy to 70\%; group 2, rats submitted to colectomy; and group 3, rats submitted simultaneously to both procedures: hepatectomy plus colectomy. In all groups, TNF and PCR were collected one hour after the surgical procedure. The animals were killed afterwards. Results: The dosage of these elements showed values with some alterations in all groups. Group three showed a significant increase of TNF $\alpha$ and decrease of PCR. Conclusion: The more complex became the surgical act the blood levels of TFN $\alpha$ have increased and the levels of the $P C R$ decreased significantly.
\end{abstract}

Key-words: Colorectal neoplasms; Hepatectomy; Colectomy; Tumor necrosis factor; Protein C; Rats, Wistar.

\section{REFERÊNCIAS}

1. Jenkins LT, Millikan KW, Bines SD, et al. - Hepatic resection for metastatic colorectal cancer. Am Surg. 1997, 63(7):605-610.

2. Fortner JG, Silva JS, Golbey RB, et al. - Multivariate analysis of a personal series of 247 consecutive patients with liver metastases from colorectal cancer. I. Treatment by hepatic resection. Ann Surg. 1984, 199(3):306-316.

3. Holm A, Bradley E, Aldrete JS - Hepatic resection of metastasis from colorectal carcinoma. Morbidity, mortality, and pattern of recurrence. Ann Surg. 1989, 209(4): 428-434.

4. Herman P, Pugliese V, D'Albuquerque LA, et al. - Tratamento cirúrgico das metástases hepáticas do câncer colorretal. Atualização em Cirurgia do Aparelho Digestivo e Coloproctologia: Gastrão. 2000, pp. 171-177.

5. Flanagan L, Foster JH - Hepatic resection for metastic cancer. Am J Surg. 1967, 113(4):551-557.

6. Vogt P, Raab R, Ringe B, et al. - Resection of synchronous liver metastases from colorectal cancer. World J Surg. 1991, 15(1):6267.

7. Bismuth H, Castaing D, Traynor O - Surgery for synchronous hepatic metastases of colorectal cancer. Scand J Gastroenterol. 1988, Suppl 23, 144-149.

8. Belghti J - Metastases hepatiques synchrones et resecables d'un cancer colo-rectal:y a-t-il un delai minimum a respecter avant de faire la resection hepatique? Ann Chir. 1990, 44(6):427429.

9. Steele G, Ravikumar TS - Resection of metastases from colorectal cancer. Biologic perspectives. Ann Surg. 1989, 210(2):127-138.

10. Elias D, Detroz B, Lasser P, et al. - Is simultaneous hepatectomy and intestinal anastomosis safe? Am J Surg. 1995, 169(2):254260.

11. Lyass S, Zamir G, Matot I, et al. - Combined colon and hepatic resection for synchronous colorectal liver metastases. J Surg Oncol. 2001, 78(1):17-21.

12. Grignani G, Maiolo A - Cytokines and hemostasis. Haematologica. 2000, 85(9):967-972.

13. Leist M, Gantner F, Jilg S, et al. - Activation of the $55 \mathrm{kDa}$ TNF receptor is necessary and sufficient for TNF-induced liver failure, hepatocyte apoptosis, and nitrite release. J Immunol. 1995, 154(3):1307-1316.

14. Miyazaki M, Kohda S, Itoh $\mathrm{H}$, et al. - Inhibition of regeneration after $70 \%$ partial hepatectomy by simultaneous resection of the bowel in rats. Eur Surg Res. 1995, 27(6):396-405.

15. Bertolino P, Klimpel G, Lemon SM - Hepatic inflammation and immunity: a summary of a conference on the function of the immune system within the liver. Hepatology. 2000, 31(6):13741378.
16. Fulop AK, Pocsik E, Brozik M, et al. - Hepatic regeneration induces transient acute phase reaction: systemic elevation of acute phase reactants and soluble cytokine receptors. Cell Biol Int. 2001, 25(7):585-592.

17. Hinggins GM, Anderson RM - Experimental pathology of the liver. Arch Pathol. 1932, 7:186-202.

18. Resection of the liver for colorectal carcinoma metastases: a multi-institutional study of indications for resection. Registry of hepatic metastases. Surgery. 1988, 103(3):278287.

19. Taylor M, Foster J, Langer B, et al. - A study of prognostic factors for hepatic resection for colorectal metastases. Am J Surg. 1997, 173(6):467-471.

20. de Saltibañes E, Lassalle FB, McCormack L, et al. - Simultaneous colorectal and hepatic resection for colorectal cancer: postoperative and long-term outcomes. J Am Coll Surg. 2002, 195(2):196-202.

21. Bakalakos EA, Kim JA, Young DC, et al. - Determinants of survival following hepatic resection for metastatic colorectal cancer. World J Surg, 1998, 22(4):399-405.

22. Yasui K, Shimizu Y, Hirai T, et al. - Surgical treatment for colorectal liver metastases - results of multi-institute study for effects of radical hepatectomy (abstract). Gan To Kagaku Ryoho, 2004, 31(5): 690-4.

23. Shimada H, Tanaka K, Masui H, et al. - Results of surgical treatment for multiple ( $>$ or $=5$ nodules) bi-lobar hepatic metastases from colorectal cancer. Langenbecks Arch Surg. 2004, 389(2):114-121.

24. Martin R, Paty P, Fong Y, et al. - Simultaneous liver and colorectal resections are safe for synchronous colorectal liver metastasis. J Am Coll Surg. 2003, 197(2): 233-241.

25. Weber JC, Bachellier P, Oussoultzoglou E, et al. - Simultaneous resection of colarectal primary tumour and synchronous liver metastases. Br J Surg. 2003, 90(8):956-962.

26. Foster JH - Surgical treatment of metastatic liver tumors. Hepatogastroenterology. 1990, 37(2):182-187.

27. Lygidakis NJ, Singh G, Bardaxoglou E, et al. - Two-stage liver surgery for advanced liver metastasis synchronous with colorectal tumor. Hepatogastroenterology. 2004, 51(56):413418.

28. Nordlinger B, Guiguet M, Vaillant JC, et al. - Surgical resection of colorectal carcinoma metastases to the liver. A prognostic scoring system to improve case selection, based on 1568 patients. Association Françoise de Chirurgie. Cancer. 1996, 77(7):12541262.

29. Bolton JS, Fuhrman GM - Survival after resection of multiple bilobar hepatic metastases from colorectal carcinoma. Ann Surg. 2000, 231(5):743-751. 
30. Sasada K, Miyazaki M, Nakagawa K, et al. - Augmented enhancement of in vitro production of inflammatory cytokines in peripheral blood mononuclear cells in patients undergoing simultaneous resection of the liver and gastrointestinal tract. Crit Care Med. 1999, 27(5):929936.

31. Koj A - Initiation of acute phase response and synthesis of cytokines. Biochim Biophys Acta. 1996, 1317(2):84-94.

32. Kushner I - The phenomenon of the acute phase response. Ann N Y Acad Sci. 1982, 389:39-48.

33. Simpson KJ, Lukacs NW, Colletti L, et al. - Cytokines and the liver. J Hepatol. 1997, 27(6):1120-1132.

34. Tilg H, Vannier E, Vachino G, et al. - Anti-inflammatory properties of hepatic acute phase proteins: preferential induction of interleukin 1(IL-1) receptor antagonist over IL-1 beta synthesis by human peripheral blood mononuclear cells. J Exp Med. 1993, 178(5): 1629-1636.

35. Ramadori G, Armbrust T - "Cytokines and liver". In Bicher F, Benhamow J-P, McIntyre N, et al. (eds) - Oxford Textbook of Clinical Hepatology. $2^{\text {nd }}$ Edition. London, Oxford University Press, 1999. pp.169-172.

36. Hoffman AL, Rosen HR, Ljubimova JU, et al. - Hepatic regeneration: current concepts and clinical implications. Semin Liver Dis. 1994, 14(2):190-210.

37. Diehl AM, Rai R - Regulation o liver regeneration by proinflamatory cytokines. J Gastroenterol Hepatol. 1996, 11(5):466-470.

38. Tsutsumi R, Kamohara Y, Eguchi S, et al. - Selective suppression of initial cytokine response facilitates liver regeneration after extensive hepatectomy in rats. Hepatogastroenterology. 2004, 51(57):701-704.

39. Yanaga K, Kanematsu K, Takenaka K, et al. - Intraperitoneal septic complication after hepatectomy. Ann Surg. 1986, 203(2):148-152.
40. Lahat N, Zlotnick AY, Shtiller R, et al. - Serum levels of IL-1, IL-6 and tumor necrosis factors in patients undergoing coronary artery bypass grafts or cholecystectomy. Clin Exp Immunol. 1992, 89(2):255-260.

41.Alcorn JM, Fierer J, Chojkier M - The acute-phase response protects mice from $\mathrm{D}$-galactosamine sensitization to endotoxin and tumor necrosis factor alpha. Hepatology. 1992, 15(1):122129.

42. Bruccoleri A, Gallucci R, Germolec DR, et al. - Induction of early-intermediate genes by tumor necrosis factor alpha contribute to liver repair following chemical induced hepatotoxicity. Hepatology. 1997, 25(1):133-141.

43. Shalaby MR, Waage A, Aarden L, et al. - Endotoxin, tumor necrosis factor alpha and interleukin-1 induce interleukin-6 production in vivo. Clin Immunol Immunopathol. 1989, 53(3): 488-498.

44. Court FG, Wemyss-Holden SA, Dennison AR, et al. - The mystery of liver regeneration. Br J Surg. 2002, 89(9):1089-1095.

45. Waitzberg DL - TNF-fator de necrose tumoral: efeitos biológicos adversos e estratégias de combate. Rev Col Bras Cir. 1995, 12(4):230-232.

46. Shenkin A, Fraser WD, Series J, et al. - The serum interleukin 6 response to elective surgery. Lymphokine Res. 1989, 8(2):123127.

47. Deitch EA - Multiple organ failure. Pathophysiology and potential future therapy. Ann Surg. 1992, 216(2):117-134.

Endereço para correnpondência:

Hamilton Luiz Funes

Rua Las Vegas, 537

Condomínio Residencial Débora Cristina

São José do Rio Preto - SP

CEP 15093-110

e-mail: hfunes@westnet.com.br 